\title{
Proceeding
}

Supplementary Issue: Summer Conferences of Sports Science. Costa Blanca Sports Science Events, 25-26 September 2020. Alicante, Spain.

\section{Analysis of the efficacy of a method for the early detection of male athletic sprinters}

\author{
FAUSTO RICARDO BAIDE-ORDOÑEZ , REIDEL CORDOVÉS-PEINADO \\ National Autonomous University of Honduras, Tegucigalpa, Honduras
}

\begin{abstract}
The research was carried out on a topic relevant to athletics, its objective was to analyse the effectiveness of a method for the early detection of male sprinters in this discipline. The idea arose from the problem taking into account the absence of a scientific way or form in Honduran athletics to guarantee the effectiveness in said process, this being a primary phase in sports initiation which is of interest to coaches, for the Honduran Federation of Athletics and the Honduran Olympic Committee as its main sponsor. The study was based on the main methods and procedures that allowed to establish the routes for the selection of talent in the area of speed, the sample of a group of children from the Garifuna coastal communities was determined for their possible inclusion in the Honduran Olympic Committee; Results were obtained in the proposed phases of identification and selection, the first allowed to determine the sports aptitude with an approach to the speed tests and the second agreed to measure the state of speed and its indicators in preparation process to specify the selection of talent, obtaining results of the functionality of the contribution after the application of tests, also the correlation between them by means of the Pearson coefficient, the expert criterion showed the acceptance of a group of competent specialists in the subject, considering that the methodology can be established.
\end{abstract}

Keywords: Efficacy; Method; Detection; Talent; Analysis.

\section{Cite this article as:}

Baide-Ordoñez, F.R., \& Cordovés-Peinado, R. (2020). Analysis of the efficacy of a method for the early detection of male athletic sprinters. Journal of Human Sport and Exercise, 15(4proc), S1512-S1526. doi:https://doi.org/10.14198/jhse.2020.15.Proc4.47

Corresponding author. National Autonomous University of Honduras, 11101 Tegucigalpa, Honduras. https://orcid.org/00000001-8403-1354

E-mail: fausto.baide@unah.edu.hn

Abstract submitted to: Spring Conferences of Sports Science. Costa Blanca Sports Science Events, 19-20 June 2020. Alicante, Spain.

JOURNAL OF HUMAN SPORT \& EXERCISE ISSN 1988-5202

(c) Faculty of Education. University of Alicante

doi:10.14198/jhse.2020.15.Proc4.47

S1512 | 2020|Proc4 | VOLUME 15

(C) 2020 University of Alicante 


\section{INTRODUCTION}

Sport as a cultural and social phenomenon of great relevance in the world today, this march along with the social, political and economic problems of the environment in which it takes place; According to Rojas (2016) "sports not only reveal social values, but also express one of the forms with the greatest impact on human development. They not only reflect a part of the dynamics of society"(p.7); but also constitute a way of reflecting society. From this statement it can be inferred that, in Honduras, the poor results obtained by sport are a direct consequence of the deficient policies undertaken by the government towards this activity. What causes the different sports federations to take measures in this regard, allowing them to survive in order to achieve a certain result.

Authors such as Platonov \& Bulatova (2007), Bompa \& Carreras (2015) have systematized in their studies that the high demands that lead to performance and results must be based on the aptitudes and natural conditions of the individual. For this reason, the gradual increase in sports performance capacity is coupled with the development trends of the physiological, biochemical, psychic components and other determinants that can only be properly recognized during the training process.

The assertion of the previous paragraph coincides with the considerations established by authors such as Noa (2006), Collazo (2006), Rodríguez \& Cols. (2010), Epstein (2014), who have recognized that issues related to performance and results in sport that, according to the considerations of Eduarte, Hernández \& Pérez (2012), have gained importance since the competitive context forces a selection more premature, having influences in later stages of the sports preparation process.

In the search for performance, the selection of talent acquires importance when a system is established to determine sports selection in a scientific way, leaving behind empirical experiences, currently recognizing different aspects such as:

A correct selection process takes into account geographical conditions, which allows for better performance and results, in the same way, contributes to the optimization of human, technical and economic resources. Consequently, it makes the process more effective in terms of quality parameters, reducing failure rates and wasted time.

Therefore, the need arises for the selection of talent to be the product of scientific knowledge, being carried out in the midst of the work carried out by the coach and physical education teachers in their environments, to which great importance is attributed. It is precisely from these activities and from the community that the child, gifted or not, takes his first steps; Therefore, the sporting performance achieved by the athlete in later stages of his sporting life cannot be separated from the moment in which he began in sport through mass incorporation.

In general, the issue of the selection of sports talents has been a rather careless plot, it is relevant to mention that in the Western Hemisphere this is considered a recent trend in the preparation of the athlete as a system.

Taking as a reference the study by Zatsiorski (1989), taking into account his historical references, we begin with the period 1960-1970 where the countries of Eastern Europe stood out for having specific methods for selecting talent, with high sports potential. They were evidenced in the spectacular results in Olympic games by the USSR and the GDR. Similarly, Bulgaria, imitated its precedents in 1976 , recognizing that $80 \%$ of the 
medallists were the result of a meticulous sports selection process, being scientifically characterized, despite these efforts, reality has continued to demonstrate the inadequacies in the scientific treatment of sports talent.

However, some researchers such as: Charles, Ruiz \& Martínez (2014), Morales (2014), Lorenzo (2015), Verdugo (2015), Rojas (2016), Posthumus \& Collins (2016), Baker, Cobley, Schorer \& Wattie. (2017), Yalama, Velasco, Calderón \& Zambrano (2017), have dealt with the selection of talent from different scientific perspectives, as well as from dissimilar sports disciplines, which at present coincide with this phenomenon as a particular process within the theory and sports training methodology.

One of the fundamental causes that has stimulated the research boom in this process is the diversity of characteristics of sports, which, according to physical, mental and technical-tactical qualities, are increasingly the alternatives that are integrated for its improvement. However, in athletics it becomes more complex because within itself the existence of dissimilar tests with different characteristics makes a system established for that sport acquire a generalizing nature and does not satisfy the needs of the different modalities, recognizing that from the From a functional point of view, the throwing, distance, jumping and racing tests are not the same, as well as those of speed and distance; they are the marked differences that makes the need to perfect in the selection of the individual.

In Honduras, the Athletics Federation and the Olympic Committee of that country work together to improve this process; through the Sports Initiation Centre, which receives athletes with special characteristics from the professional technical work of the country's instructors and technicians, who are in constant search of sports talent through the use of methods that guarantee compliance with these objectives, supported by the criteria of many of the aforementioned authors. However, and despite the achievements made to date; These issues continue to be a focus of concern for coaches and other specialists in charge.

In this sense, during the review of different training control documents in the athletics area in the Sports Initiation Centre, a decrease was detected in terms of the indicators of promotion of athletes in the area of speed in athletics. In this sense, a tool was developed which in this research aims to evaluate the efficacy of a method for the early detection of male sprinters in the Garifuna communities of the cities of Tela, La Ceiba and Trujillo.

\section{METODO}

\section{Participants}

It was determined from a universe of 42 students between the 5th and 6th year of schooling, from the communities of Tela, Ceiba and Trujillo in the department of Atlántida, with an average age between 12.88 and 13.85 years.

The sample was considered simple random probabilistic, taking into account that all have the same possibility of being selected from within the population that has been defined, they were listed and the sample was calculated.

Having made these definitions, a sample by groups was randomly selected from each population, a multistage sampling form, in which schools were first chosen and then a sub-sample by groups of students enrolled in the year 2018-2019, taking into account this aspect the Inclusion criteria were: having received the athletics unit in the physical education class, having been evaluated as satisfactory in the physical 
education class, representativeness of both sexes with an equitable approach; in this sense, which was constituted as follows:

Table 1. All the students chosen as a research sample.

\begin{tabular}{lcc}
\hline Municipality & 12 Year Old Students & 13 Year Old Students \\
\hline Tela & 7 & 5 \\
Ceiba & 5 & 9 \\
Trujillo & 8 & 8 \\
Total & 20 & 22 \\
\hline
\end{tabular}

\section{Measurement instruments and techniques used}

The instruments and tests selected are the following:

Diagnostic measurements: It will be taken into account in the performance measurement in the physical and psychomotor tests carried out, as well as the specific measurements in the speed tests that will be carried out in the corresponding stage, in this sense the following will be applied:

Simple reaction test to a moving object

In this case, the exposed test is used in order to evaluate the child's reaction, which is necessary for a future sprinter in athletics. The coach holds a ball or other specific object at the level of the child's sight, who places the palm of his hand over that of the researcher. When he drops the object, the child will try to catch it.

Complex reaction test to a moving object

In this test, operational thinking or game intelligence is tested, putting children to solve the problem of the quick choice of a response action. It is carried out as in the simple reaction to a moving object, with the difference that the researcher holds two objects or small balls: but both of different colours. In this case, the child is given a more complex task, the ball or object of one colour should try to catch it, and the other should try to hit it with the palm of the hand. The child does not know which of the two objects will fall, that is, the balls are released randomly, trying to ensure that the number of launches of one and the other ball is equal. For each child, 10 attempts should be used.

\section{Speed test}

The basic 30-meter race test will be used, it is used in the athletics unit in the basic national curriculum of Physical Education of Honduras, therefore, we consider it relevant considering the stage in which the child is and their familiarization with the test. Located at the goal, the researcher will begin to take the time from the child's first movement with the rearmost leg until his arrival at the end. The timed time is recorded in hundredths of a second.

Procedures to establish the method for the early detection of talent in the area of speed in athletics in Honduras.

The steps to follow to achieve the development of the research will be carried out from the distribution of the following phases:

1. The first step is the diagnosis, which, based on the application of tests to measure sports fitness, will allow a first approach to the characteristics associated with speed with the sample in general, which will allow to have the first discrimination in the initial phase of talent identification, three moments of evaluation will be taken into account. 
2. Second step, taking into account the group of students who were selected in the identification phase, they are incorporated into the training process, taking into account the constant adjustments in their preparation, consolidating the content base necessary for the correct location and execution of the low snatch, correct displacement, the skills for the correct displacement with the metatarsal, the elevation of the thighs. In this sense, three measurements will be made where the state of the speed and its indicators will be evaluated (acceleration by sections, speed by sections and time per meters travelled), this will allow obtaining data for the Pearson correlation test, determining the content validity.

3. Third step the application of expert criteria, which will contribute to the validity of the content is established, through the logical analysis that the author has reached in the elements included in his tests and the acceptance and contributions issued by the experts.

Next, to facilitate understanding, the following diagram is presented, which represents the steps to follow:

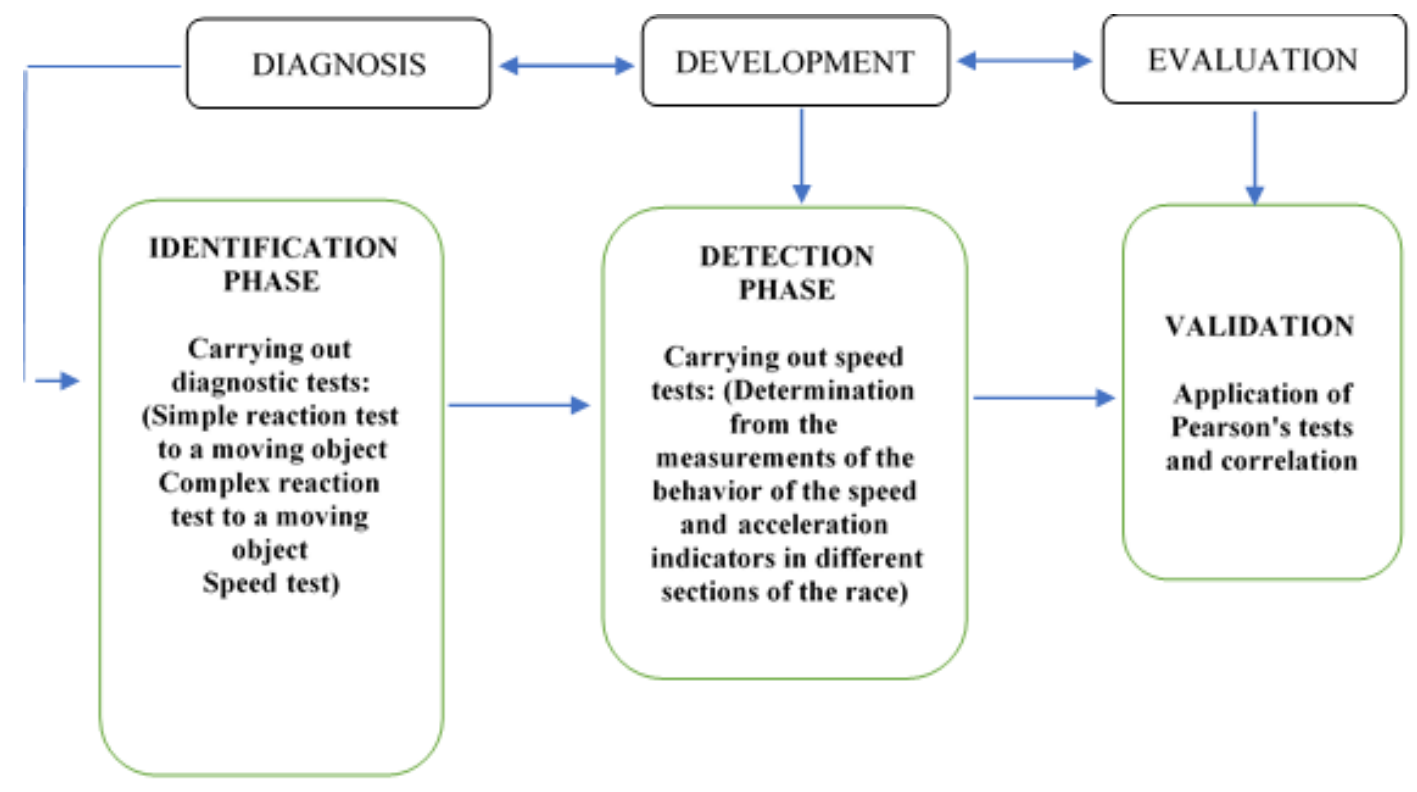

Figure 1. Representation of procedures.

Mathematical statistical procedures for the velocity area and to demonstrate the feasibility of the investigation.

In the first phase, it will be carried out through the determination of general averages in each of the indicators, the mode and the deviation, in order to discriminate those children with results lower than or equal to the mean. In this sense, it will allow proposing the lower limit may be based on logical criteria, by assessing the highest quality in terms of a certain variable with high desirable values in the group of children to be evaluated, the specialists suggest that its upper quality limit for the sports selection in the physical efficiency test to the studied sample.

In the second phase, the feasibility of the investigation in this case the method that is proposed will be carried out from the measurement of the speed and acceleration indicators, in this sense, the averages are determined, the deviation in each of the distances measured by runners, allowing determine results above the group mean. Then, the Pearson correlation index is applied between the tests performed. 
In the third phase, the proposal is corroborated by applying the tests to determine the Pearson coefficient between them from the results.

\section{RESULTS}

Results of the diagnosis in the talent identification phase

Table 2. Table of results of the first round of tests.

\begin{tabular}{|c|c|c|c|c|c|c|c|}
\hline Children & Size & Weight & Speed & Coord. & $\begin{array}{c}\text { Simple } \\
\text { Reaction }\end{array}$ & $\begin{array}{l}\text { Complex } \\
\text { Reaction }\end{array}$ & $\begin{array}{l}\text { Distribution of } \\
\text { attention change (s) }\end{array}$ \\
\hline & 163 & 57 & 5.48 & 7.32 & 5.09 & 4.39 & 43.75 \\
\hline & 164 & 58 & 5.51 & 7.24 & 5.93 & 4.23 & 42.68 \\
\hline & 162 & 53 & 5.61 & 7.36 & 6.04 & 4.44 & 45.72 \\
\hline & 159 & 50 & 5.78 & 7.39 & 6.21 & 4.38 & 44.77 \\
\hline & 164 & 56 & 5.69 & 7.35 & 6.18 & 4.53 & 45.81 \\
\hline & 166 & 60 & 5.61 & 7.40 & 6.00 & 4.40 & 45.67 \\
\hline & 160 & 51 & 5.70 & 7.31 & 6.07 & 4.36 & 46.02 \\
\hline & 161 & 62 & 5.50 & 7.32 & 6.17 & 4.39 & 44.93 \\
\hline & 163 & 54 & 6.01 & 7.32 & 6.08 & 4.40 & 45.80 \\
\hline & 162 & 54 & 5.97 & 7.34 & 6.31 & 4.32 & 45.68 \\
\hline & 160 & 52 & 5.89 & 7.29 & 6.04 & 4.31 & 45.52 \\
\hline & 160 & 53 & 6.11 & 7.33 & 5.79 & 4.38 & 45.88 \\
\hline & 157 & 50 & 5.61 & 7.33 & 5.94 & 4.39 & 45.55 \\
\hline & 159 & 51 & 5.70 & 7.38 & 6.20 & 4.39 & 45.60 \\
\hline & 162 & 51 & 5.64 & 7.41 & 6.33 & 4.32 & 45.71 \\
\hline & 158 & 49 & 5.51 & 7.32 & 6.19 & 4.35 & 45.70 \\
\hline & 169 & 62 & 5.61 & 7.30 & 6.00 & 4.37 & 45.72 \\
\hline & 161 & 57 & 5.66 & 7.28 & 5.82 & 4.41 & 45.77 \\
\hline & 162 & 58 & 5.59 & 7.58 & 6.16 & 4.52 & 45.68 \\
\hline & 163 & 57 & 5.70 & 7.39 & 5.90 & 4.30 & 45.68 \\
\hline & 163 & 57 & 6.10 & 7.83 & 5.55 & 4.34 & 45.76 \\
\hline & 162 & 60 & 5.84 & 7.55 & 6.10 & 4.37 & 45.70 \\
\hline & 159 & 51 & 6.09 & 7.92 & 6.04 & 4.41 & 45.72 \\
\hline & 165 & 58 & 5.85 & 7.61 & 6.02 & 4.40 & 45.72 \\
\hline & 162 & 58 & 5.61 & 7.50 & 6.14 & 4.36 & 45.68 \\
\hline & 157 & 54 & 5.61 & 7.29 & 5.99 & 4.37 & 45.68 \\
\hline & 161 & 58 & 5.62 & 7.39 & 6.09 & 4.33 & 45.69 \\
\hline & 162 & 60 & 5.61 & 7.32 & 5.88 & 4.45 & 45.70 \\
\hline & 160 & 57 & 5.60 & 7.37 & 6.11 & 4.42 & 45.63 \\
\hline & 164 & 58 & 5.95 & 7.32 & 6.04 & 4.39 & 45.55 \\
\hline & 159 & 56 & 5.51 & 7.40 & 6.12 & 4.39 & 45.78 \\
\hline & 166 & 59 & 5.61 & 7.44 & 5.81 & 4.39 & 45.70 \\
\hline & 163 & 54 & 5.60 & 7.52 & 6.02 & 4.39 & 45.72 \\
\hline & 159 & 56 & 5.61 & 7.42 & 6.00 & 4.39 & 45.69 \\
\hline & 160 & 58 & 5.63 & 7.39 & 5.80 & 4.39 & 45.73 \\
\hline & 161 & 59 & 5.61 & 7.52 & 5.91 & 4.39 & 45.76 \\
\hline & 162 & 55 & 5.78 & 7.43 & 6.10 & 4.39 & 45.78 \\
\hline
\end{tabular}


As summary measures of the data, and to characterize the determining indicators of sports fitness in the population, the sample values of the arithmetic mean and the standard deviation of each of them were used. The results obtained with the 12-year-old children are shown; which in turn constitute punctual estimates of the respective parameters of their source population. The test of difference between means, mode and estimated deviation as a whole, in three moments interspersed in a process indicated that the differences established between the variables, in this sense, in each of the moments were discriminating those that presented with results lower than the half.

Detailing: the observed differences in speed and coordination are on the order of tenths of a second. In practical terms, for sporting purposes, such differences are not considered important for speed in athletics. In this way, when the morpho-physiological particularities due to age, sex and the nervous system of 12year-old children are analysed, it indicates that, although during this period there are obvious differences in the behaviour of children.

The constant intrinsic biological variations to which human beings are subjected, such as: weight, height, weight and colour of individuals cover a space that reflects significant variations, which may exist in subjects, but in a different way. not unlimited.

The table shows the regression coefficients found, with which the weights of the variables evaluated as contributors to the natural sports aptitude of 12-year-old children from the municipalities of Tela, Ceiba and Trujillo were found.

Table 3. Discrimination results from the second round of testing.

\begin{tabular}{cccccccc}
\hline Children & Size & Weight & Speed & Coord. & $\begin{array}{c}\text { Simple } \\
\text { Reaction }\end{array}$ & $\begin{array}{c}\text { Complex } \\
\text { Reaction }\end{array}$ & $\begin{array}{c}\text { Distribution of } \\
\text { attention change (s) }\end{array}$ \\
\hline 163 & 58 & 5.45 & 7.32 & 5.09 & 4.39 & 43.75 \\
164 & 57 & 5.44 & 7.24 & 5.93 & 4.23 & 42.68 \\
162 & 51 & 5.58 & 7.36 & 6.04 & 4.44 & 45.72 \\
164 & 54 & 5.55 & 7.35 & 6.18 & 4.53 & 45.81 \\
166 & 63 & 5.59 & 7.40 & 6.00 & 4.40 & 45.67 \\
163 & 59 & 6.01 & 7.32 & 6.08 & 4.40 & 45.80 \\
162 & 53 & 5.97 & 7.34 & 6.31 & 4.32 & 45.68 \\
160 & 56 & 6.11 & 7.33 & 5.79 & 4.38 & 45.88 \\
162 & 55 & 5.64 & 7.41 & 6.33 & 4.32 & 45.71 \\
169 & 65 & 5.61 & 7.30 & 6.00 & 4.37 & 45.72 \\
161 & 58 & 5.66 & 7.28 & 5.82 & 4.41 & 45.77 \\
162 & 59 & 5.59 & 7.58 & 6.16 & 4.52 & 45.68 \\
163 & 56 & 5.70 & 7.39 & 5.90 & 4.30 & 45.68 \\
163 & 56 & 6.10 & 7.83 & 5.55 & 4.34 & 45.76 \\
162 & 59 & 5.84 & 7.55 & 6.10 & 4.37 & 45.70 \\
165 & 58 & 5.85 & 7.61 & 6.02 & 4.40 & 45.72 \\
162 & 59 & 5.61 & 7.50 & 6.14 & 4.36 & 45.68 \\
161 & 59 & 5.62 & 7.39 & 6.09 & 4.33 & 45.69 \\
162 & 60 & 5.61 & 7.32 & 5.88 & 4.45 & 45.70 \\
160 & 59 & 5.63 & 7.39 & 5.80 & 4.39 & 45.73 \\
162 & 60 & 5.61 & 7.52 & 5.91 & 4.39 & 45.76 \\
163 & 58 & 5.78 & 7.43 & 6.10 & 4.39 & 45.78 \\
\hline
\end{tabular}


The results in the second round of tests, after the process, the children improved the indicators of simple reaction, coordination, body weight and speed were, in that order, the variables with the greatest contribution. Such results will be observed in the next table, as well as later in the general differences obtained in the three evaluation moments, from the determination of those children with results below the collective mean were rejected for the next round.

Table 4. Table of results of the third discriminatory round of tests.

\begin{tabular}{cccccccc}
\hline Children & Size & Weight & Speed & Coord. & $\begin{array}{c}\text { Simple } \\
\text { Reaction }\end{array}$ & $\begin{array}{c}\text { Complex } \\
\text { Reaction }\end{array}$ & $\begin{array}{c}\text { Distribution of } \\
\text { attention change (s) }\end{array}$ \\
\hline 164 & 57 & 5.44 & 7.24 & 5.93 & 4.21 & 42.60 \\
& 166 & 63 & 5.59 & 7.38 & 6.00 & 4.39 & 44.68 \\
161 & 60 & 5.50 & 7.32 & 6.17 & 4.37 & 44.72 \\
162 & 59 & 5.58 & 7.47 & 6.14 & 4.30 & 44.61 \\
& 162 & 60 & 5.61 & 7.30 & 5.88 & 4.40 & 45.56 \\
160 & 57 & 5.54 & 7.44 & 6.37 & 4.39 & 45.51 \\
\hline
\end{tabular}

The results obtained can be considered so stable as to be useful for the next uptake in the speed area, taking into account the results to establish a regulation for the fulfilment of programs, in the same way, inclusion is allowed according to upcoming results or some change abrupt demographic, or that the indicators are varied.

Results of the comparison between the parameters of mean, mode and deviation in the three test moments

Table 5. Comparative result of the average in the three rounds of tests.

\begin{tabular}{lccccccc}
\hline Average & Size & Weight & Speed & Coord. & $\begin{array}{c}\text { Simple } \\
\text { Reaction }\end{array}$ & $\begin{array}{c}\text { Complex } \\
\text { Reaction }\end{array}$ & $\begin{array}{c}\text { Distribution of } \\
\text { attention change (s) }\end{array}$ \\
\hline Moment. 1 & 161.52 & 56.28 & 5.7076 & 7.4114 & 6.0098 & 4.3846 & 45.5838 \\
Moment. 2 & 162.71 & 58.31 & 5.67 & 7.40 & 6.01 & 4.39 & 45.57 \\
Moment. 3 & 163.33 & 58.71 & 5.57 & 7.37 & 6.00 & 4.36 & 44.97 \\
\hline
\end{tabular}

Table five shows the results of positives attending from moment one to the third, in this sense, the relationship of weight with speed is observed, taking into account the first and the decrease in time in the translation of the movement, in the same way, improves behaviour in reactions and coordination.

Table 6. Behaviour of fashion in the three test moments.

\begin{tabular}{lccccccc}
\hline Average & Size & Weight & Speed & Coord. & $\begin{array}{c}\text { Simple } \\
\text { Reaction }\end{array}$ & $\begin{array}{c}\text { Complex } \\
\text { Reaction }\end{array}$ & $\begin{array}{c}\text { Distribution of } \\
\text { attention change (s) }\end{array}$ \\
\hline Moment. 1 & 162.00 & 58.00 & 5.61 & 7.32 & 6.04 & 4.39 & 45.7 \\
Moment. 2 & 162.00 & 59.00 & 5.61 & 7.32 & 6.00 & 4.39 & 45.72 \\
Moment. 3 & 162 & 63 & 5.59 & 7.3 & 6 & 4.36 & 45.78 \\
\hline
\end{tabular}

The significant differences established are taken into account that we are present before actions of relatively short time, therefore, since there is a short distance travelled in the speed movements, the coordination and reaction exercises allow to demonstrate that the third specific moment in those more homogeneous children Through its improvements during the process, it is possible to deduce greater susceptibility to workloads; the results are shown in the table. 
Table 7. Results of the deviation of the three moments.

\begin{tabular}{lccccccc}
\hline Average & Size & Weight & Speed & Coord. & $\begin{array}{c}\text { Simple } \\
\text { Reaction }\end{array}$ & $\begin{array}{c}\text { Complex } \\
\text { Reaction }\end{array}$ & $\begin{array}{c}\text { Distribution of } \\
\text { attention change (s) }\end{array}$ \\
\hline Moment. 1 & 2.70 & 3.91 & 0.21 & 0.15 & 0.21 & 0.05 & 0.54 \\
Moment. 2 & 2.23 & 3.34 & 0.16 & 0.12 & 0.23 & 0.05 & 0.62 \\
Moment. 3 & 2.44 & 3.51 & 0.05 & 0.09 & 0.25 & 0.07 & 1.11 \\
\hline
\end{tabular}

\section{Results in the talent selection phase}

Three speed tests were carried out, taking into account a period of 15 days between them, taking into account that the process in this phase lasted a total of 45 days; In this sense, the results in the 30-meter test were determined, distributed in the different selected distances in which the runners were measured, taking the time in each space to determine the speed indices taking into account the speed indicators by section, acceleration per section and the time per meters travelled by the 6 runners evaluated.

In runner No. 1 of the sample obtained satisfactory results in attending to the tests carried out, showing evolution in each of the distances that were measured during a race; In this sense, under approximately 1.6 thousandths of a second in the last test with respect to the first, in the graph that is presented below, the speed reached in $\mathrm{m} / \mathrm{s}$ in each of the distances is observed.

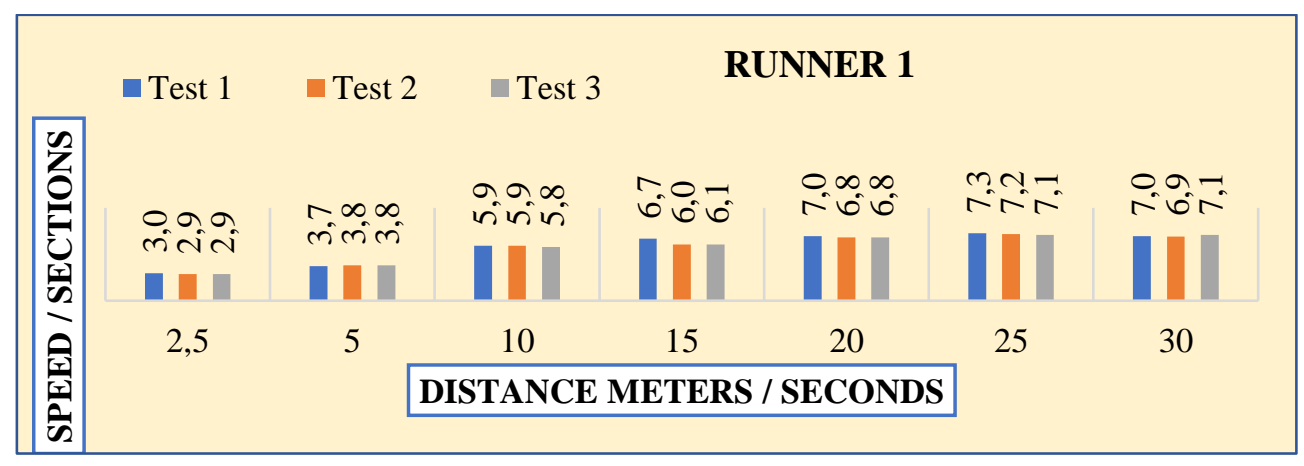

Figure 2. Behaviour of runner 1 in the three tests carried out in the selection phase.

Runner No. 2 was characterized by showing stability in each of the tests, showing few significant differences between them, in this sense, he showed acceleration between 5 and 20 meters of distance in order to stabilize during the rest of the race.

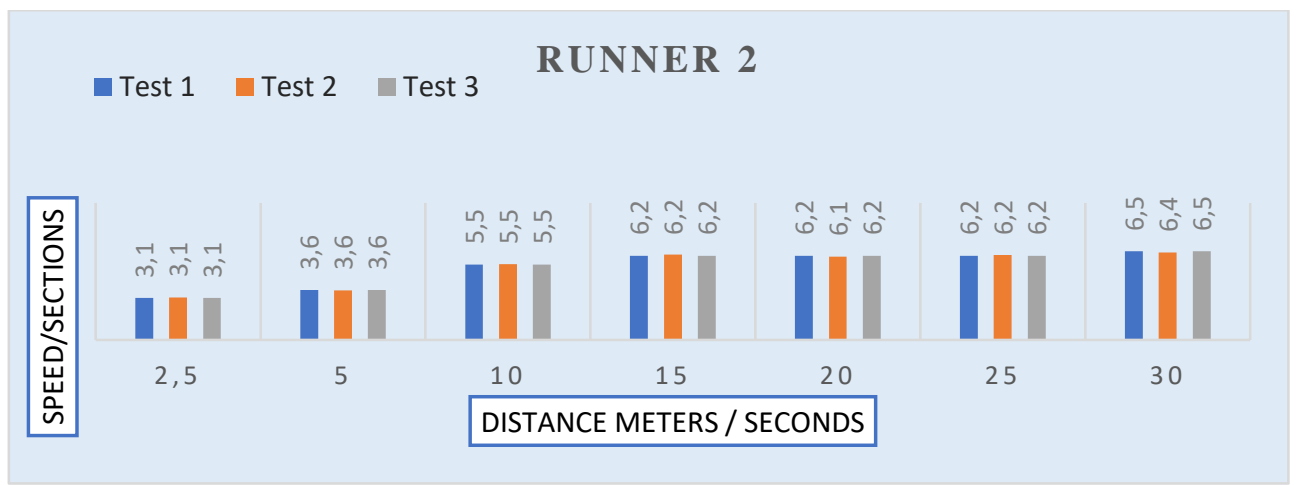

Figure 3. Behaviour of runner 2 in the three tests carried out in the selection phase. 
Runner No. 3. obtained better results in the two initial tests before in the third; Consequently, it did not show progression during the process despite having better or similar times to the rest of those evaluated, it is also due to the fact that it reaches its maximum acceleration between 5 and 15 meters away, showing a good reaction and good traffic toward acceleration.

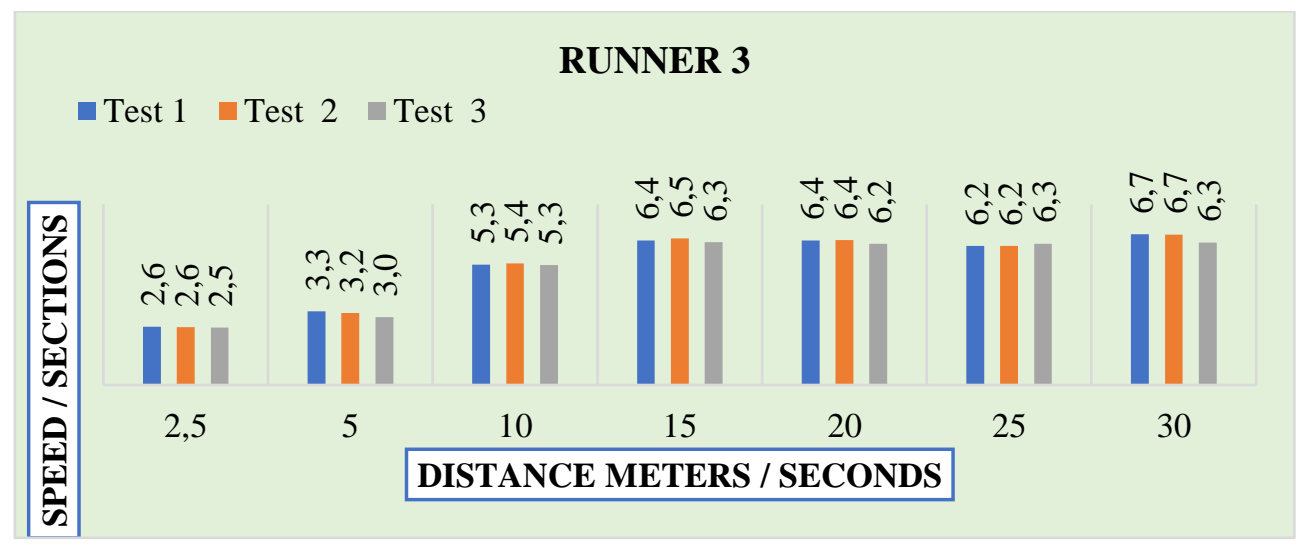

Figure 4. Behaviour of runner 3 in the three tests carried out in the selection phase.

Runner No. 4 showed good progression during the tests evaluated, however, in the third test approximately 15 meters away a technical failure did not allow him to maintain the proper speed, taking into account this aspect, a marked undulation is observed in the acceleration within 20 meters of distance, which would not be normal if this accidental situation had not occurred.

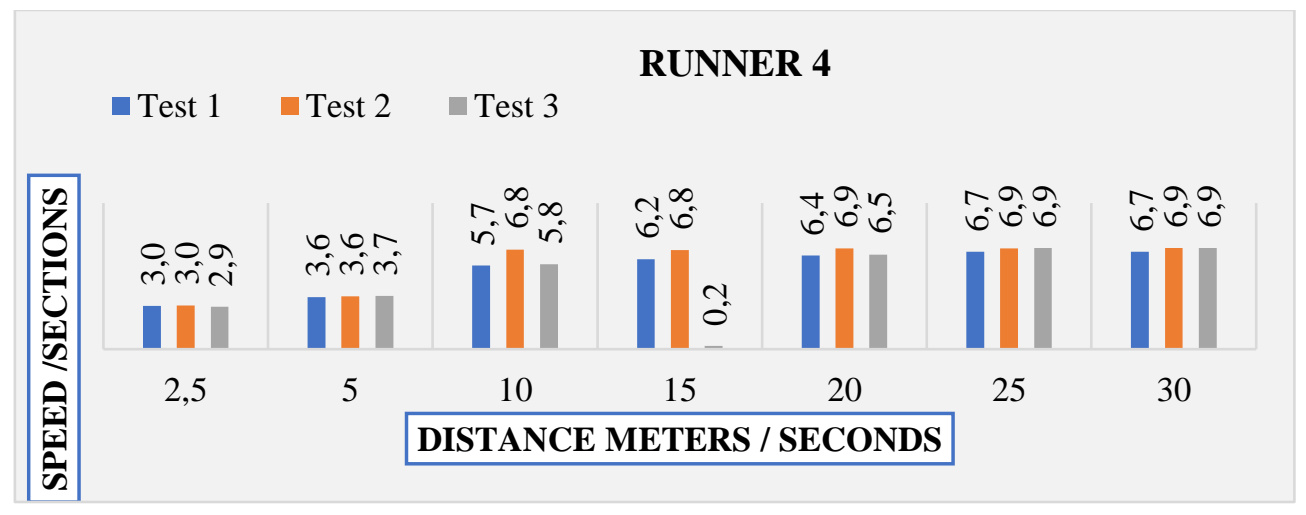

Figure 5. Behaviour of runner 4 in the three tests carried out in the selection phase.

The corridor No. 5 in the performance of the three tests showed evolution, it is interesting that the one evaluated in the distances from 20 meters, showed variation of the upward acceleration, this being one of the characteristics that identifies it from the rest having capacity Reserve for the final moment of the race, he was the one with the best speed with 7.9234 meters per second after passing the 30 meters of distance covered by the test, this situation being stable in moments 1 and 2 of evaluation. 


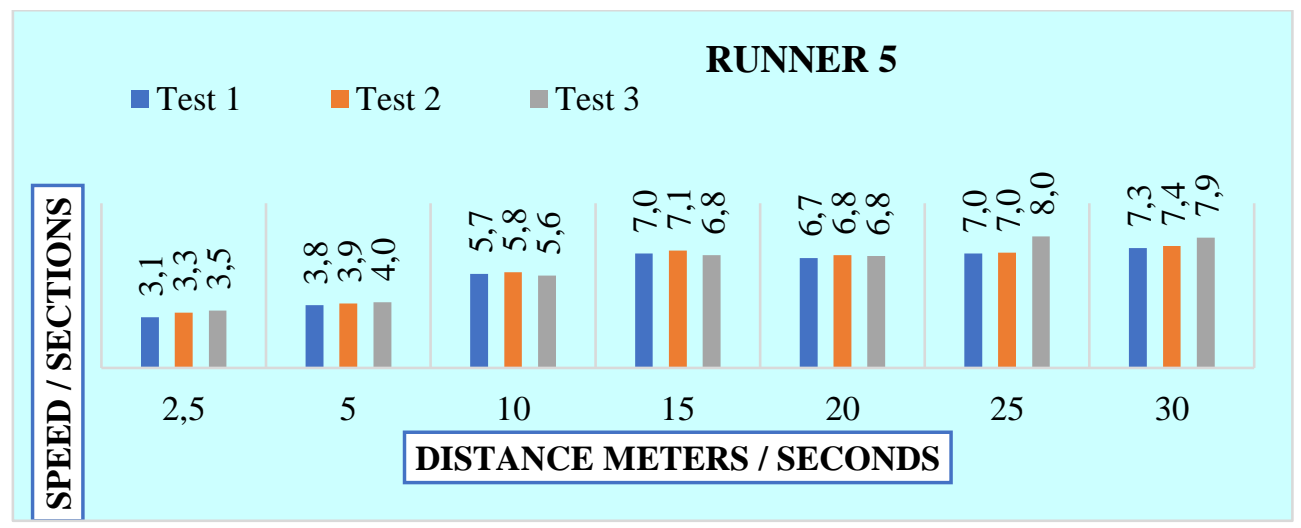

Figure 6. Behaviour of runner 5 in the three tests carried out in the selection phase.

Runner No. 6 showed the evolutionary nature of the group in terms of the three tests carried out, taking into account its progression in the three moments evaluated, it stands out as one of those that reaches the highest speed in the last 30 meters of distance.

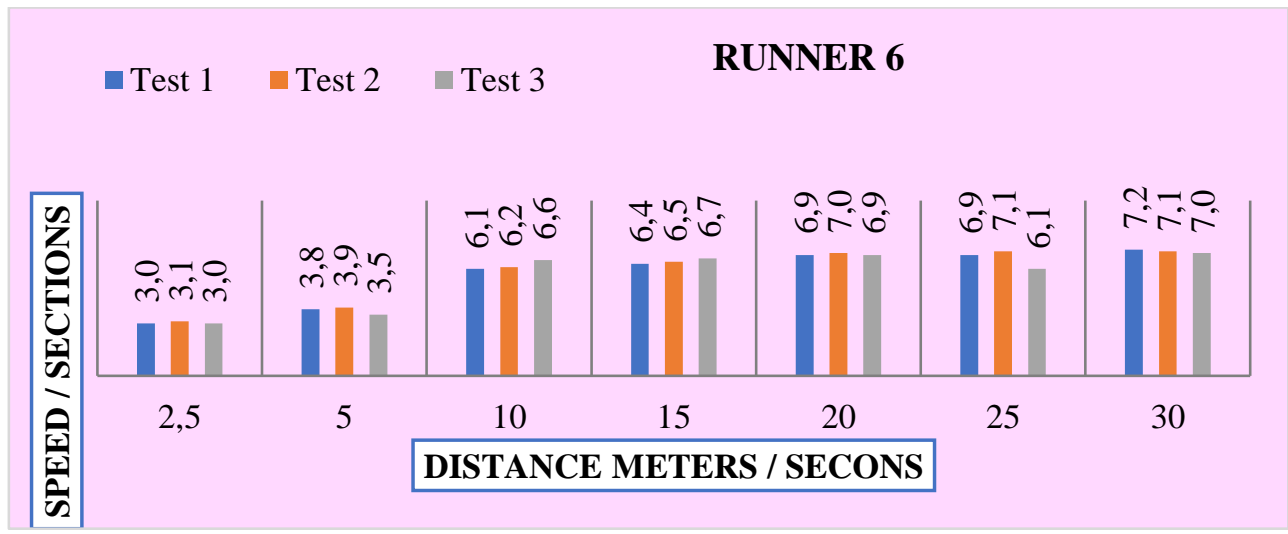

Figure 7. Behaviour of runner 6 in the three tests carried out in the selection phase.

\section{Results of the correlation between the tests performed}

The correlation between the three tests performed was carried out where the results were averaged between them; In this sense, the Pearson coefficient and the Determination are determined in each of the distances travelled, from the data presented in the tables of annexes 1,2 and 3; This made it possible to identify the behaviour between the tests carried out taking into account the indicators of acceleration by sections and speed by sections; The following results are presented below:

Table 8. Results of Pearson's coefficient and determination.

\begin{tabular}{lccccccc}
\hline \multirow{2}{*}{ Indicators } & \multicolumn{7}{c}{ Distances measured during the race } \\
\cline { 2 - 8 } & $2.5 \mathrm{~m}$ & $5 \mathrm{~m}$. & $10 \mathrm{~m}$. & $15 \mathrm{~m}$. & $20 \mathrm{~m}$. & $25 \mathrm{~m}$. & $30 \mathrm{~m}$. \\
\hline Pearson coefficient & 0.6088 & 0.8089 & 0.3487 & 0.5519 & 0.5898 & 0.32234 & 0.0028 \\
Determination & 0.3706 & 0.6544 & 0.1216 & 0.3046 & 0.3478 & 0.10390 & $8 \mathrm{E}-06$ \\
\hline
\end{tabular}

The evaluation will be obtained according to the Pearson correlation coefficient evaluation criterion shown in the following table: 
Table 9. Evaluative criterion of Pearson's coefficient and determination.

\begin{tabular}{|l|l|}
\hline$R=-1$ & Perfect inverse correlation \\
\hline $1<r<0$ & Inverse correlation \\
\hline$R=0$ & There is no correlation \\
\hline $0<r<1$ & Direct correlation \\
\hline$R=1$ & Perfect direct correlation \\
\hline
\end{tabular}

Taking into account the results obtained between the tests, a direct correlation is shown between the variables acceleration per section and speed per section, with relative values greater than zero and less than one $(0<r<1)$. This means that the values obtained in the averaged coefficient oscillate around .52 , which shows a direct correlation, but with moderate force, in this sense it shows that the proportionality between the variables recognizing that when acceleration increases, speed increases.

\section{DISCUSSION}

From the achievement of a methodology contextualized to the characteristics in the training processes, in it from two essential moments, one of diagnosis that incorporated the detection of talent as an initial phase; Consequently, the measurements were carried out on the basis of physical and psychosocial indicators, in such a way that they allowed to identify the qualities of the children for sports practice, in this case, it was not based solely on a descriptive basis through obtaining The averages, but also the recognition of the mean, the mode and the deviation contributed to the existing differences in the tests, allowing to establish the rejection values by quality, and the values that delimit the route of each indicator in the population, in order to discriminate in three moments to specify the group of the selection phase.

In the second moment, the children selected in the first phase were incorporated into the preparation process, this allowed adjusting technical details that contributed to the improvement in the race, in order to evaluate the state of speed in three moments and select the true possible talents, this way of proceeding is considered novel, since on the grab of a single sample they were discriminated until they found those identified as talents. Acceleration indicators and speed by sections were taken into account, which showed the level of development in the children and were essential for the researcher's claims.

This way of selection and evaluation experienced for the athletics in the area of speed, allowed to evaluate in the course the effectiveness of the training and to take measures to eliminate any imbalance; therefore, it fulfils the regulatory function of the system, taking into account the results obtained in each test, also allowing the fluctuations to be assessed, which as a group can occur from one year to the next.

Consequently, the average behaviour of children in the tests in the distance of 50 meters, has a tendency to distribute the effort in a regular way, thus pretending to perform a high average speed. This is important considering that the greatest difficulty that the future sprinter and the coach must overcome is in finding the right effort to achieve maximum speed percentages that can best be kept constant throughout the entire competition distance.

Therefore, to have a vision of the scope of our future talents, it is estimated in relation to competitive speed taking into account the distances of 100 and 200 meters, it is a problem of high average speed and not of instantaneous speed as previous research has materialized. This analysis coincides with the approximate distribution of efforts made by the selected children; In this sense, they reach the maximum speed at 25-30 
meters and obtain a sub-maximum speed between 40-45 meters; which indicates that there is a space between 30 and 40 meters in which children recover from the effort.

However, it is convenient to make clear that said reduction in maximum effort is hardly noticeable; therefore, it is complex to determine nervous energy consumption and savings based on effort; However, in the tests carried out, what is determined in the decrease in speed carried out by children in the 30-40 meter stretch leads to a remarkable recovery of nervous energy; evidenced when they increase the speed in the section between 40 and 45 meters; the decrease in speed in the final part of the test always occurs, whether in the case of children in initiation, but with this we can have an approach to deductions that the children have tried to spend a good time in the test; trying, within their possibilities, to maintain an average speed as high as possible.

These results demonstrated the effectiveness and usefulness of the experimented methodology, which together with the result of direct correlation between the fundamental variables acceleration and speed by means of the Pearson correlation, demonstrated a good level of performance efficiency, although it is also recognized that other variables intervene in this process, such as energy expenditure, lactic acid levels in the race among others that can be correlated with the variables studied, this would also require looking for another correlation mechanism that responds to compare with greater wealth of information, in order to contribute to determine in a better way the degree of use of the motor potential that allows establishing predictive values that are referential as marks to be achieved, for these ages in the speed tests of Honduran athletics.

Taking into account the aforementioned aspects, it can be said that we are facing an authentic and successful study, since the study and establishment of the method in stages that lead to the achievement of the objectives of establishing a method for the selection of talent in sprinters through its effectiveness ; Such an aspect that distinguishes this research with respect to the antecedents, taking into account selection criteria and indicators according to the specific characteristics of the sprinter, taking an approach to the regional norms to evaluate the aptitudes of children.

One cannot fail to point out that although the institution of reference in the investigation, the Initiation Centre of the Olympic Committee of Honduras, has the relevant conditions to develop this type of work, it does not mean that it can be applied in other spaces, Like schools through the athletics unit in physical education, let us remember that the educational space is the first link at the base of the pyramid of sports selection for the detection of talent towards high performance.

Therefore, there are spaces for discussion, debate, including other investigations that may influence physical education through school sports, this would bring results in terms of the processes for the selection of talent, moving away from empiricism; also that the characteristics of children in the territory of Tela is not the generality of the country, therefore, it is necessary to significantly increase the sample to achieve a country regulation, recognizing that genetics is essential for speed.

\section{CONCLUSIONS}

The application of the methodology for the selection of talent in athletics for the speed area, has allowed to verify that; it has the ability to eliminate empiricism and subjectivity and that contributes to raising the quality of this process and thus sports results; despite the fact that it takes longer to reach high levels of research validation. The effectiveness of the methodology was demonstrated from its viability from the technical and 
organizational order, the usefulness of the selected tests, the relevance of the indicators with the speed in athletics, as well as the ability to solve the tests verified by through the correlation between the fundamental variables acceleration and speed per section; which allows making the right decisions about the future of practicing children in terms of their possibilities in sport and early specialization, demonstrating its functionality.

\section{REFERENCES}

Baker, J., Cobley, S., Schorer, J. y Wattie, N. (2017) Talent identification and development in the context of growing up. University of Bath, Department for Health Centre for Motivation and Health Behaviour Change. https://doi.org/10.4324/9781315668017

Bompa, T. y Carreras, M. (2015) Conditioning young athletes. USA: Editorial. Human Kinetics.

Charles, C.M., Ruiz, S.J., and Martínez, P.R. (2014). The recruitment of sports talents, conceptual approaches. Physical Education and Sports, Buenos Aires Digital Magazine, 19 (194) 1-7.

Calero, S. and González, S. (2015) Physical and sports preparation. Wait. University of the Armed Forces.

Capetillo, R. (2010). The identification of sports talents for open skill sports. Lúdica Pedagógica Magazine, 2 (15) 148-155.

Collazo, M. A and Cols. (2006). Theory and methodology of sports training. Volume II. City of Havana, Digitized.

CONDEPAH (2017) Methodological requirements for the development of sports talent in Honduras.

Dorticós, F. León, G., Del Toro, M. and Cols. (2016) Selection and development of sports talent. A proposal in the school environment. Technological Institute of Sonora.

Du Randt, R. (2008) Talent identification in sport: practices and issues. CME: Your SA Journal 352. Academic One File. Web.

Eduarte, L., Hernández, A. and Pérez, P. (2012) Behavior of the level of knowledge about the sports initiation process in the ages of 9 to 12 for the sport of basketball in Cienfuegos. Physical Education and Sports, Digital Magazine, Buenos Aires 17 (174) 1-3.

Epstein, D. (2014) The sports gene: is an excellent athlete born or made? Barcelona, Spain: Editorial Indices.

Gozzoli, Simohamed, El-Hebil (2006) Mini Athletics Instruction Cards IAAF, Kids Athletics.

Granados, C. I. (2007). Differences in physical fitness and throwing velocity among elite and amateur female handball players. International Journal of Sports Medicine, 10, 860. https://doi.org/10.1055/s2007-964989

Hernández, C.M. (2000) Biomechanical control system to provide feedback for the 100-meter dash (Doctoral Thesis in Pedagogical Sciences), University of Matanzas, Cuba 210-215.

Hoare, D. (2001). Talent Identification and Selection Handbook. Australia: SISA.

Lorenzo, L. J. (2015). And if we forget about talent detection ... and if we individualize the process of developing their talent. Madrid, Spain: University of Salamanca Editions.

Martínez, Y., Carralero, A. (2017) Strategy in the selection of talents in the athletics sport in the ages of 10 and 11 years, prior to entry into the provincial EIDE. According to demographic and sociological characteristics. UNICA Magazine.

Montero J. G. (2015). Methodology for managing sports talent selection processes. (Didactic Programming of the Training Program "Technological Management of Sports). South Sports University. Venezuela.

Morales, S. (2014). Sociocultural strategy for selection and sports initiation. Colima: University of Colima. 11-12. 
Noa, H. (2006) Study on the selection of soccer talent for initiation to high performance sports. (Doctoral Thesis, University of Las Palmas Gran Canarias) University of Las Palmas, Gran Canarias.

P, J. M. (2006). Proposal for a new sports talent detection model. Valencia, Spain: Editorial Meliana.

Platonov, V. Bulatova, M. (2007) Physical preparation. Barcelona, Spain: Editorial Paidotribo.

Posthumus, M. y Collins, M. (2016) Genetics and Sports. https://doi.org/10.1159/isbn.978-3-318-03011$\underline{2}$

Rodríguez, A. Leyva, H. and García, M.A. (2010) Proposal of indicators for the selection of baseball sports talents, based on the massive practice of sport in the community of Sibanicú, Camagüey. Physical Education and Sports, Digital Magazine, Buenos Aires 15 (148), 1-2.

Rojas, M. (2016) Values in the practice of sport at the Francisco Morazán National Pedagogical University. (Master's Thesis on Physical Education Teaching) Francisco Morazán National Pedagogical University, Tegucigalpa, Honduras.

Santis, C. (2005). Manual for the recruitment and sports initiation in athletics. Government of Chile, Chiledeportes.

Verdugo, F. (2015). The biological maturation process and sports performance. Chilean Journal of Pediatrics, 86 (6), 1-2.

Wuitar, C. M., Caveda, D. L., and García, M. R. (2018). Technical and biomedical study to detect talents in athletics. Cuban Journal of Biomedical Research, 37 (1), 1-12.

Yalama, S., Velasco, W., Calderón, Á. and Zambrano, Z. (2017) Evaluation of the women's 60 meter dash in the 14-15 year old school category in athletics. Physical Education and Sports, Digital Magazine, Buenos Aires 22 (235), 1-2.

Zatsiorski, V. (1989). Sports metrology. Havana, Cuba: Editorial Pueblo.

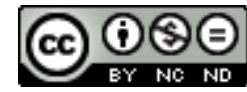

This work is licensed under a Attribution-NonCommercial-NoDerivatives 4.0 International (CC BY-NC-ND 4.0). 